\title{
Tokuhashi Scoring System has limited applicability in the majority of patients with spinal cord compression secondary to vertebral metastasis
}

\author{
A Escala de Tokuhashi possui aplicabilidade limitada na maioria dos pacientes \\ com compressão medular secundária à metástase vertebral
}

Matheus Fernandes de Oliveira, Breno de Amorim Barros, Jose Marcus Rotta, Ricardo Vieira Botelho

\begin{abstract}
Spine is the primary bone site affected by systemic metastasis. Although there are scales that attempt to manage these patients, their real applicability is unknown. The Tokuhashi Scoring System (TSS) is a widely used prognostic tool. At the time of treatment, the data necessary to complete TSS may be incomplete, making its application impossible. Objective: To evaluate the number of TSS scores completed by the time the clinical therapeutic decision was made. Methods: From July 2010 to January 2012, we selected patients who were diagnosed with spinal metastases. Results: Sixty spinal metastasis patients (21 female, 39 male) were evaluated between July 2010 and January 2012. At the time of the treatment decision, only $25 \%$ of the patients had completed the TSS items. Conclusion: In the majority of patients with vertebral metastasis, TSS variables cannot be applied.
\end{abstract}

Keywords: neoplasm metastasis, spinal diseases, prognosis.

\section{RESUMO}

A coluna vertebral é o sítio ósseo mais acometido na doença neoplásica metastática. Embora haja escalas que buscam normatizar o tratamento destes pacientes, sua real aplicabilidade é incerta. A Escala de Tokuhashi (TSS) é uma ferramenta prognóstica vastamente empregada. No momento do tratamento, os dados necessários ao preenchimento da escala podem estar incompletos, tornando sua aplicação inviável. Objetivo: Avaliar o número de TSS completos até a tomada de decisão terapêutica. Métodos: De Julho de 2010 a Janeiro de 2012 , selecionamos pacientes diagnosticados com metástases espinhais. Resultados: Sessenta pacientes foram avaliados durante o período; destes, 21 eram mulheres e 39, homens. Até a tomada de decisão, foi possível completar os itens da TSS em apenas 25\% dos pacientes. Conclusão: Na maioria dos pacientes com metástases espinhais, a TSS não pôde ser aplicada.

Palavras-chave: metástases, doenças da coluna vertebral, prognóstico.

Chronic degenerative diseases and cancer have been highlighted as major causes of morbidity and mortality in aging populations ${ }^{1-3}$. Up to $40 \%$ of cancer patients will develop skeletal metastases; the spine, because of its size, contiguity, and rich vascularization, is the primary affected bone site ${ }^{1-4}$. Among patients who develop spinal metastases, only 5-10\% develop epidural spinal cord compression, and $10 \%$ of those patients will be symptomatic ${ }^{1-7}$ (Figure 1).

Although there are numerous scales and questionnaires that attempt to adequately manage these patients, little attention is given to the real applicability of these tools and their prognostic implications. The Tokuhashi Scoring System $(\mathrm{TSS})^{8,9}$ is a widely used prognostic tool and has a significant predictive value in comparison to other scales ${ }^{10,11}$.

The TSS is complex and consists of six areas: the clinicaloncological pattern represented by the Karnofsky score (KS), other neurological measurements (Frankel scale), and four other areas that depend on knowledge of the primary tumor site and other data for rating the tumor stage (extra spinal bone metastases, spinal metastases, and metastases of major 

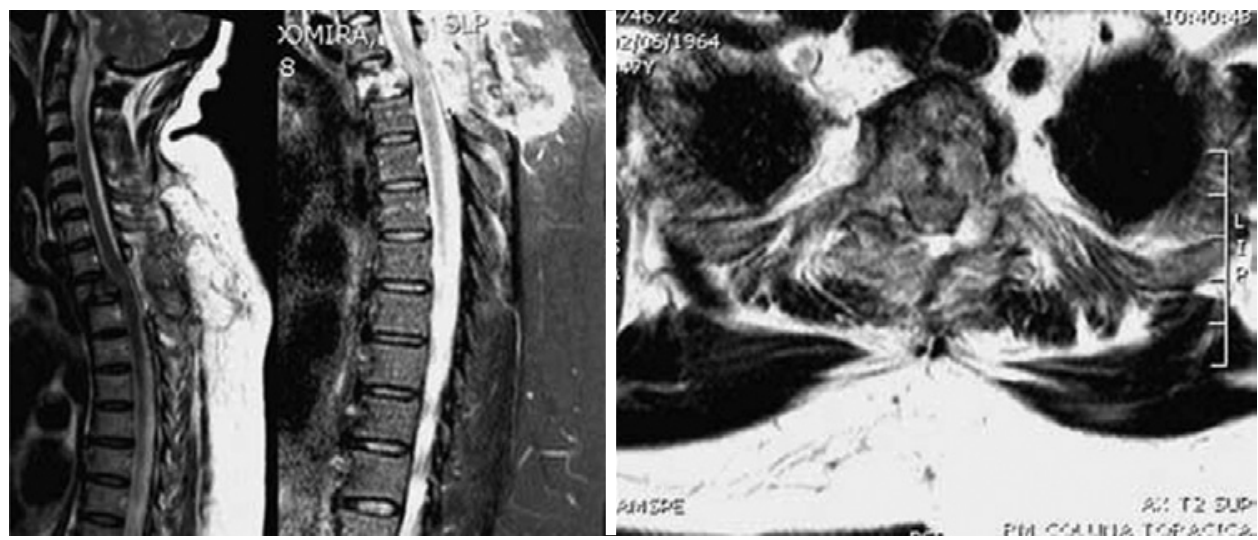

Figure 1. Left: MRI images of a 47-year-old female patient with no previous oncological history who presented with acute paraparesis and a pathologic fracture of T3 with anterior spondylolisthesis causing spinal cord instability and compression. Hyperintensity of the spinal cord was observed at the level of critical compression. Middle: Image revealing intense contrast uptake by the tumor and the surrounding soft tissue. Right: Axial slice revealing critical compression of the spinal cord with obliteration of the CSF spaces. The patient underwent immediate surgical decompression and posterior stabilization.

internal organs). Each domain generates a specific score and determines a sum that guides the treatment toward conservative, palliative, and/or excisional. The proportion of patients who have sufficient data for the TSS (to determine utility until the decision-making) $)^{12,13}$ is unknown.

\section{OBJECTIVE}

To evaluate the percentage of patients with sufficient data to apply TSS prediction to treatment decision making.

\section{METHODS}

Patients with a known or suspected diagnosis of spinal metastases who were consecutively admitted to the Hospital do Servidor Público Estadual de São Paulo (HSPE) were evaluated with the TSS from July 2010 to January 2012. The project was approved by the Research and Ethics Committee of HSPE.

The patients received complete neurological examinations, and the Frankel scale and the following TSS items were collected (if available) until therapeutic decisions were made: neurological and general clinical condition (as described on the KS), the number of bony extra-spinal metastases (measured with skeletal scintigraphy with Technetium-99), the number of metastases in the vertebral bodies (measured by a neuroaxis magnetic resonance image [MRI] of the entire spine and/or scintigraphy of the skeleton), the number of metastases in important internal organs (measured by a chest and abdominal computed tomography [CT[ scan), breast and gynecological evaluations, and a specific search for the primary cancer sites.

The decision making consisted of performing surgery, radiotherapy or biopsy.

\section{Statistics}

The numerical data are described as mean \pm standard deviation. The categorical data are presented as percentages. Student's t-tests were used for the paired and unpaired groups as appropriate. The significance level was established as $\mathrm{p}<0.05$.

\section{RESULTS}

Sixty spinal metastasis patients were evaluated from July 2010 to January 2012. Of these patients, 21 were female and 39 were male. The average age was $60.52 \pm 11.69$ for women and $63.20 \pm 10.54$ for men. There was no statistically significant difference between the ages of the groups ( $p>0.05)$.

Among the 60 patients, only 2 were asymptomatic, both of whom were referred from the oncology department after an active search for metastasis. Eighteen patients presented with spinal pain: 23 because of neurological deficits and 17 because of both pain and neurological deficits.

Only 15 patients (25\%) completely fulfilled the TSS.

All of the patients were neurologically (Frankel scale) and clinically (KS) evaluated. Neurologically, 6 patients presented with complete deficit (Frankel A), 3 with Frankel B, 23 with Frankel C, 12 with Frankel D, and 16 with Frankel E (Figure 2).

The KS in our sample varied from 30 to 90 . Three patients (5\%) presented with a KS of 30, 7 patients with 40, 13 patients with 50, 19 patients with 60,6 patients with 70,6 patients with 80, and 5 patients with 90 (Figure 3 ).

Fifteen of the 60 patients (25\%) were evaluated with bone scintigraphy. All 15 showed spinal uptake; 5 of these patients presented with diffuse skeletal uptake; and 3 presented with skull, sternum, and rib uptake.

Until the therapeutic decision was made, no patient was given an entire neuroaxis MRI evaluation due to time constraints and MRI availability. In contrast, all of the patients 


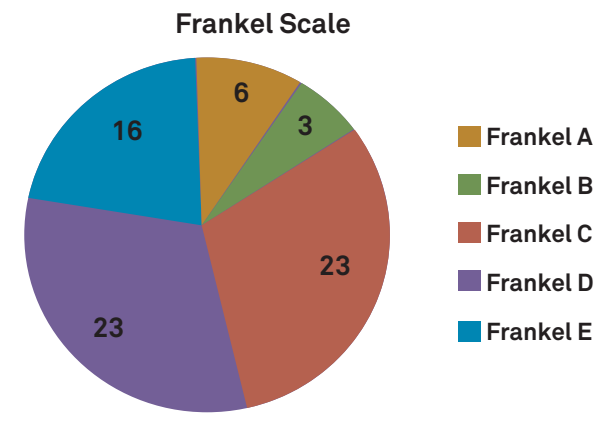

Figure 2. Neurological status of patients at admission, presented as the Frankel scale.

\section{Karnofsky Score}

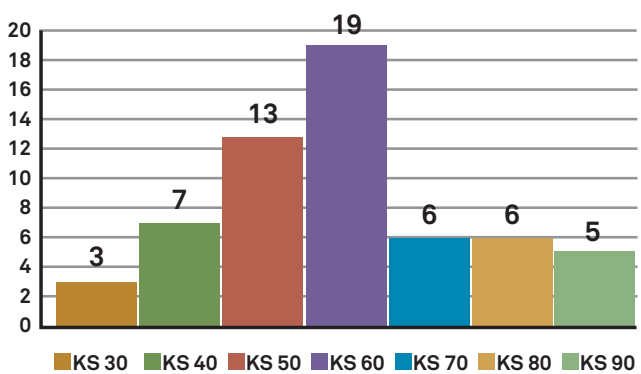

Figure 3. Patient's clinical status at admission (Karnofsky Score - KS)

underwent local spine MRIs directed at the spinal cord compression site.

In this study, $78 \%$ of spinal metastases were localized in the thoracic spine, $41 \%$ in the lumbar spine, $13 \%$ in the cervical spine, and $10 \%$ in the sacral spine.

Before the treatment decision was made, only $25 \%$ of patients had undergone bone scintigraph y, 30\% had received thoracic and abdominal tomography, and no patient had a complete spine MRI evaluation.

In the search for metastases in important internal organs, only 18 patients were evaluated by a thoracic or abdominal CT scan. In five of these cases, only diffuse lymphadenopathy was noted; pulmonary nodules were observed in four cases, liver metastasis in three, and pleural thickening in one.

Thirty-nine of the 60 (65\%) patients had received a histopathological diagnosis prior to admission. Of these diagnoses, 11 were in the breast, 11 were in the prostate, and 5 were in the lung; 4 patients had multiple myeloma, 3 had colon cancer, and 2 had non-Hodgkin's lymphoma. Bladder, kidney, and larynx cancer were reported by one patient each (Figure 4).

The TSS was not completely fulfilled in $75 \%$ of patients (Table); rather, the decisions concerning conservative, palliative, and excisional treatment were based on clinical, neurological, and imaging data.

Fifty-five percent of patients were treated conservatively with radiotherapy; $33 \%$ underwent a decompression-only approach, decompression was added to a spine fixation in $5 \%, 4 \%$

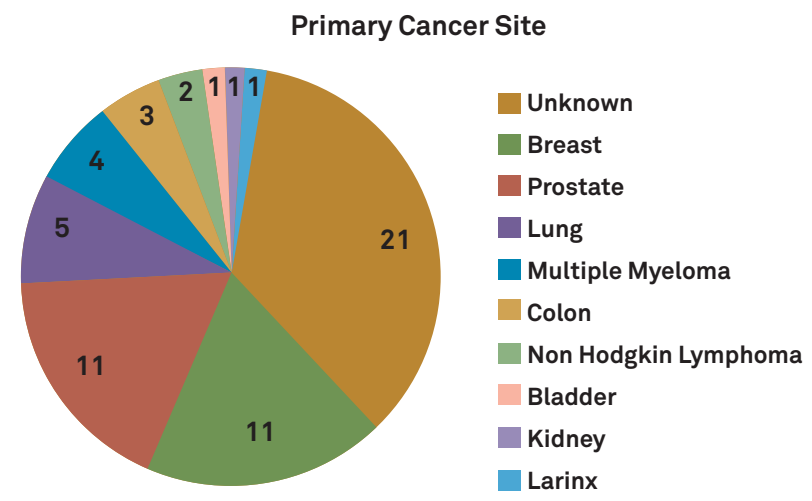

Figure 4. Primary cancer sites at admission.

Table 1. The percentage of patients able to fulfill each TSS item at the time of decision making.

\begin{tabular}{lc}
\hline TSS item & Completed (\%) \\
\hline General condition (Karnofsky) & $100 \%$ \\
Neurological status (Frankel) & $100 \%$ \\
Primary cancer site & $65 \%$ \\
Metastases in important internal organs & $30 \%$ \\
Metastases in vertebral bodies & $25 \%$ \\
Bone metastases in extra-spinal sites & $25 \%$ \\
\hline
\end{tabular}

only underwent a diagnostic percutaneous biopsy, and an anterior decompression approach was used in $3 \%$ of cases.

\section{DISCUSSION}

The TSS is a tool used to determine survival prognosis. The extent and complexity of disease management depends on the patient's prognosis and life expectancy; patients with life expectancies less than 6 months are treated conservatively or with palliative surgery, a life expectancy of 6 to 12 months involves palliative surgery, and the expectation for patients with a life expectancy greater than 12 months is excision surgery ${ }^{12,13}$.

Prognostic prediction scales should be based on accessible data. Metastatic disease is a predictor of poor outcome in cancer patients; in particular, metastatic disease has a high potential of mortality, morbidity, and definitive neurological deficits, such as paraplegia and paraparesis. Time is the main factor involved; delayed clinical or surgical treatments may generate irreversible neurological deficits ${ }^{7}$.

In our sample, most of the patients who sought treatment for symptomatic spinal metastases presented with few neurological deficits, and they were healthy enough for surgery.

A full evaluation of all the TSS variables requires sophisticated imaging diagnostic tools with expensive, complex, time consuming, and not always readily available sources. Only a quarter of our patients were able to completely satisfy the requirements for the TSS before the decision-making process. 
Many other systems to predict the prognosis and guide decision making are available, such as the Sioutos, Tomita, Van der Linden, and Bauer scores. The TSS has been the most widely accepted and used scoring system, and it has significant predictive value ${ }^{14-18}$. However, every score, even with its particularities, requires complete evaluation of the systemic disease, including a histological diagnosis. Several authors have demonstrated that the primary tumor site is the most important prognostic factor for patient survival, and this is well accepted ${ }^{19}$.

However, in vertebral metastasis with spinal cord compression, there is an urgent need for decision-making, and the histological diagnosis and tumor staging data require time that is not available before treatment ${ }^{7}$. The histological diagnosis of primary cancer requires a prior sample for analysis, sample fixation, slide preparation, staining, and immunohistochemical analysis for a definitive diagnosis. This could take 2 to 5 days using standard services. A bone scintigraphy study protocol also demands several hours for completion. CT scans of the vital organs and MRI require fasting time and the availability of equipment.

Although the apparatuses for diagnosis are present in the study hospital, clinical and neurological conditions and the specific protocols of radiological studies do not allow for full patient assessment before surgery. Furthermore, complete evaluations sometimes require the use of more than one device, which undoubtedly dramatically increases the time required to complete the tests.

The urgent treatment of vertebral metastasis still remains paramount to protect spinal cord vitality ${ }^{1,2,6,8,11,14-17}$. Cancer staging data were absent in the majority of our cases until the moment of therapeutic intervention in the spinal cord compression cases.

Thus, some authors maintain that the surgical decision criteria should be based on clinical and neurological disorders instead of prognostic scales ${ }^{1,20}$. Our results support those views. Although diagnostic equipment was available, the neurological status associated with patient health is urgent, and the multiplicity of required tests prevents complete fulfillment of the TSS before making a treatment decision. To our knowledge, the applicability of the TSS in clinical conditions outside research protocols has not been previously evaluated in the literature. Therefore, our reasoning appears to be a novelty.

\section{CONCLUSIONS}

In the majority of patients with vertebral metastasis, TSS variables were incomplete, and the system was not useful in guiding treatment types.

\section{References}

1. Kilbride L, Cox M, Kennedy CM, Lee SH, Grant R. Metastatic spinal cord compression: a review of practice and care. J Clin Nurs 2010;19:1767-1783.

2. Paton GR, Frangou E, Fourney DR. Contemporary treatment strategy for spinal metastasis: the "LMNOP" system. Can J Neurol Sci 2011;38:396-403.

3. Shiue K, Sahgal A, Chow E, et al. Management of metastatic spinal cord compression. Expert Rev Anticancer Ther 2010;10:697-708.

4. Bauer HC, Tomita K, Kawahara N, Abdel-Wanis ME, Murakami H. Surgical strategy for spinal metastases. Spine (Phila Pa 1976) 2002;27:1124-1125.

5. Bauer HC, Wedin R. Survival after surgery for spinal and extremity metastases. Prognostication in 241 patients. Acta Orthop Scand 1995;66:143-146.

6. Bilsky MH, Lis E, Raizer J, Lee H, Boland P.The diagnosis and treatment of metastatic spinal tumor. Oncologist 1999;4:459-469.

7. Choi D, Crockard A, Bunger C, et al. Review of metastatic spine tumor classification and indications for surgery: the consensus statement of the Global Spine Tumour Study Group. Eur Spine J 2010;19:215-222.

8. Hessler C, Vettorazzi E, Madert J, Bokemeyer C, Panse J. Actual and predicted survival time of patients with spinal metastases of lung cancer: evaluation of the robustness of the Tokuhashi score. Spine (Phila Pa 1976) 2011;36:983-989.

9. Tokuhashi Y, Matsuzaki H, Oda H, Oshima M, Ryu J. A revised scoring system for preoperative evaluation of metastatic spine tumor prognosis. Spine (Phila Pa 1976) 2005;30:2186-2191.

10. Tokuhashi Y, Matsuzaki H, Toriyama S, Kawano H, Ohsaka S. Scoring system for the preoperative evaluation of metastatic spine tumor prognosis. Spine 1990;15:1110-1113.

11. Hirabayashi H, Ebara S, Kinoshita T, et al. Clinical outcome and survival after palliative surgery for spinal metastases: palliative surgery in spinal metastases. Cancer 2003;97:476-484.

12. Itshayek E, Yamada J, Bilsky M, et al. Timing of surgery and radiotherapy in the management of metastatic spine disease: a systematic review. Int J Oncol 2010;36:533-544.

13. Leithner A, Radl R, Gruber G, et al. Predictive value of seven preoperative prognostic scoring systems for spinal metastases. Eur Spine J 2008;17:1488-1495

14. Papastefanou S, Alpantaki K, Akra G, Katonis P. Predictive value of Tokuhashi and Tomita scores in patients with metastatic spine disease. Acta Orthop Traumatol Turc 2012;46:50-56.

15. Polly DW Jr, Chou D, Sembrano JN, Ledonio CG, Tomita K. An analysis of decision making and treatment in thoracolumbar metastases. Spine (Phila Pa 1976) 2009;34(22 Suppl):S118-S127.

16. Putz C, Wiedenhöfer B, Gerner HJ, Fürstenberg CH. Tokuhash prognosis score: an important tool in prediction of the neurological outcome in metastatic spinal cord compression: a retrospective clinical study. Spine (Phila Pa 1976) 2008;33:2669-2674.

17. Tomita K, Kawahara N, Kobayashi T, Yoshida A, Murakami H, Akamaru T. Surgical strategy for spinal metastases. Spine (Phila Pa 1976) 2001;26:298-306

18. Ulmar B, Huch K, Naumann U, et al. Evaluation of the Tokuhashi prognosis score and its modifications in 217 patients with vertebral metastases. Eur J Surg Oncol 2007;33:914-919.

19. Wibmer C, Leithner A, Hofmann G, et al. Survival analysis of 254 patients after manifestation of spinal metastases: evaluation of seven preoperative scoring systems. Spine (Phila Pa 1976) 2011;36:1977-1986.

20. Botelho RV, Oliveira MF, Rotta JM. Quantification of vertebral involvement in metastatic spinal disease. The Open Orthopaedics Journal 2013; In Press. 